科学 通 报

\title{
若尔盖高原泥炭 $\delta^{13} \mathrm{C}$ 的初步研究 ${ }^{*}$
}

\author{
王富喵阎革
}

(南京大学大地海洋科学系, 南京 210008)

\author{
林 本 海 \\ (中国科学院西安黄士与第四纪地质开放研究实验毞, 西安 710061)
}

\section{关键词若尔盖高原、有机碳 $\boldsymbol{\delta}^{13} \mathrm{C} 、$ 晚仙女木期}

若尔盖高原位于 $32^{\circ} 20^{\prime}-34^{\circ} 10^{\prime} \mathrm{N}, 102^{\circ} 15^{\prime}-102^{\circ} 50^{\prime} \mathrm{E}$, 海拔 $3600 \mathrm{~m}$, 为我国高海拔泥 炭发育的主要地区. 厚达数胀到十数米的泥炭储存着晚冰期以来环境变化的大量信息, 是研究 青藏高原东部近期环境变化最理想的材料之一. 红原泥炭有机碳 $\delta^{13} \mathrm{C}$ 稳定同位素组成曲线

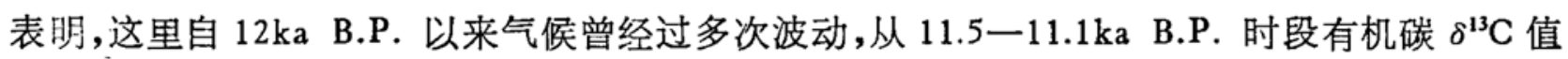
的剧烈变化推测,可能存在晚仙女木期低温事件.

样品采自红原县泥炭二矿, 海拔 $3505 \mathrm{~m}$, 此处原为沼泽地, 目前沼泽已基本停止发育. 我 们在相距不到 $50 \mathrm{~m}$ 同高度的两个地点各挖一剖面, 剖面 $\mathrm{I}$ 厚 $4.60 \mathrm{~m}$, 地表为厚 $26 \mathrm{~cm}$ 的高山 草甸土, 其下为厚 $4.2 \mathrm{~m}$ 的泥炭层; 底部为一细粉砂与淤泥质土层, 厚度大于 $25 \mathrm{~cm}$; 测得底部

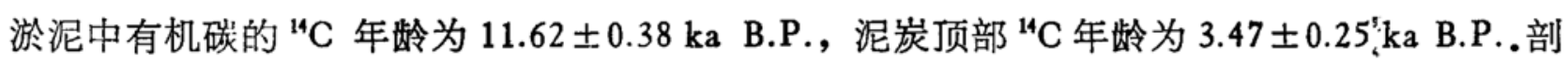
面 II 顶部为泥炭, 以下为灰色粘土质粉砂夹泥炭沉积, 局部夷树枝及谇木块, 厚 $5.3 \mathrm{~m}$; 顶部 粉砂土中树枝的 ${ }^{14} \mathrm{C}$ 年龄为 $9.63 \pm 0.32 \mathrm{ka}$ B.P., 底部为 $14.72 \pm 0.47 \mathrm{ka}$ B.P.. 因此, 连接两剖 面可得到距今 $15 \mathrm{ka}$ 至 $3 \mathrm{ka}$ 左右的一个连续剖面.

对剖面 I、II 共取 65 个样品, 分别进行了有机碳 $\delta^{13} \mathrm{C}$ 、有机碳含量、孢粉、化学元素等 项目的分析测定. 样品的时距为 $180-240$ 年. 用作有机碳 $\delta^{13} \mathrm{C}$ 分析的试样为莎草科植物 残体, 经综合分析, 认为上述剖面泥炭中的碳同位素组成未受后期改造, 故其有机碳 $\delta^{13} \mathrm{C}$ 曲线 的环境意义可靠. 本文主要讨论 $11.6-3.5 \mathrm{ka}$ B.P. 时段的环境变化. 有机碳 $\delta^{13} \mathrm{C}$ 的测定采 用“安瓶法”[1], 分析所用仪器为 Finigen Model-251 型质谱仪, 采用的标准为 PDB, 测量误 差 $<0.2 \%$.

根据分析测试结果绘成的有机碳 $\delta^{13} \mathrm{C}$ 曲线如图 1 所示. 从图中可以看出:

1. 各个时期形成的泥炭有机碳 $\delta^{13} \mathrm{C}$ 值偏负的程度较一般湖泊沉积高, 达 $-28.0 \% 0$ 左右. 究其原因有二, 一是因为莎草科植物属 $\mathrm{C}_{4}$ 植物, 其 $\delta^{13} \mathrm{C}$ 值的分布较低, 为 $-12-20 \% 0^{[2]}$; 二 是本文所采用方法提取作有机碳 $\delta^{13} \mathrm{C}$ 分析用样品实质上相当于树轮分析中的全木. 经实验 证实, 用全木作 $\delta^{13} \mathrm{C}$ 分析所得结果较用 $\alpha$-纤维素所得值为负, 但两者之间存在很好的相关关 系,相关系数 $\gamma=0.61^{[3]}$.

2. 就各时段有机碳 $\delta^{13} \mathrm{C}$ 值的变幅而言, 在 $11.6-10.5 \mathrm{ka}$ B.P. 时段为最大, 超过 $2.4 \%$, 其 后的有机碳 $\delta^{13} \mathrm{C}$ 曲线趋于平稳，虽然其间也有小的波动，但幅度较小，一般不超过 $0.8 \%$ 。

本区泥炭主要由未完全分解的莎草科植物残体堆积而成. 这种植物只在夏季生长, 通过

1992-04-27 收稿, 1992-08-03 收修改稿.

冰国家自然科学基金及西安黄士与第四纪地质开放研究实验室资助项目. 


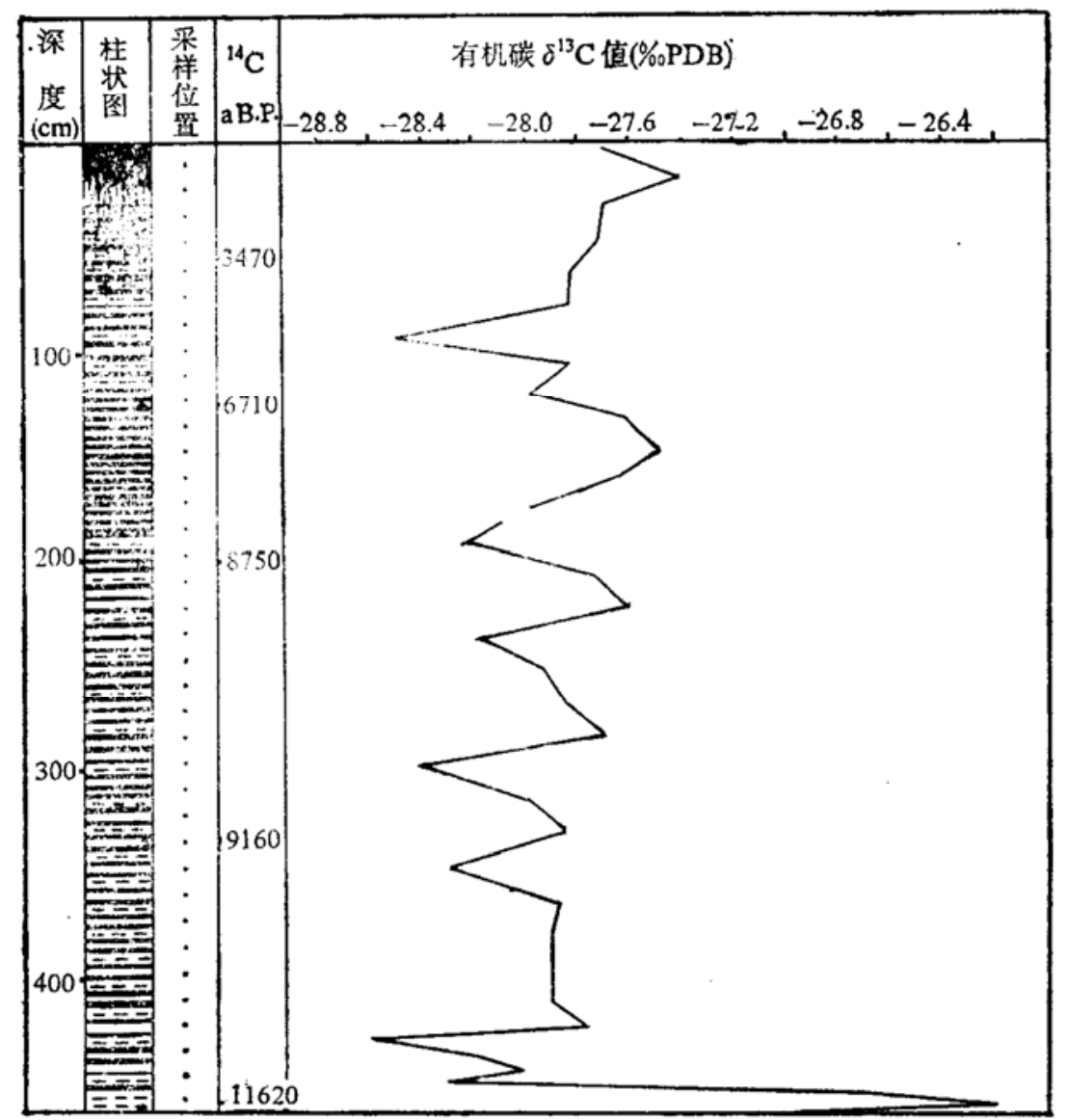

图 1 红原泥炭二矿泥炭有机碳 $\delta^{13} \mathrm{C}$ 分布曲线

光合作用固定大气中的 $\mathrm{CO}_{2}$ 以合成自身的组成物质. 由于轻、重同位素在热运动或生化反应 过程中的活动性不同, 植物在吸收 $\mathrm{CO}_{2}$ 进行光合作用时, 则导致碳同位素的分馏. 此分馏作 用直接或间接的受当时的气候状况影响, 因此泥炭的有机碳 $\delta^{13} \mathrm{C}$ 值可以作为指示形成泥炭时 莎草科植物生长季节气候状况的指标之一. 莎草科植物为 $\mathrm{C}_{4}$ 植物, 在夏季生长旺盛, 这样研 究生长季内的气候状况实际上已转化为研究该地夏季气候状况.

若尔盖高原现代气象资料表明,本区夏季处于高温多雨的西南季风控制下,同时还受副热 带高压的影响. 莎草科植物虽属 $\mathrm{C}_{4}$ 植物, 但其光合途径则是 $\mathrm{C}_{4}$ 和 $\mathrm{C}_{3}$ 途径的综合体, $\mathrm{C}_{4}$ 途 径所固定的 $\mathrm{CO}_{2}$ 最终须经 $\mathrm{C}_{3}$ 途径才能被同化合成. 为了讨论方便, 我们以 $\mathrm{C}_{3}$ 途径中稳定 同位素的分馏模式来讨论气候状况对 $\mathrm{C}_{4}$ 植物碳同位素分馏的影响 ${ }^{[4]}$.

$$
\delta^{13} \mathrm{C}_{\mathrm{p}}=\delta^{13} \mathrm{C}_{\mathrm{a}}-4.4-22.6\left(P_{\mathrm{i}} / P_{\mathrm{a}}\right),
$$

(1) 式中 $\delta^{13} \mathrm{C}_{\mathrm{p}}$ 为植物纤维素中的 $\delta^{13} \mathrm{C}$ 值, $\delta^{13} \mathrm{C}_{4}$ 为植物生长季内大气 $\mathrm{CO}_{2}$ 中的 $\delta^{13} \mathrm{C}$ 值; $P_{\mathrm{i}}$ 和 $P_{2}$ 分别是纤维素细胞内部和外部的 $\mathrm{CO}_{2}$ 局部压力.

鉴于全木的 $\delta^{13} \mathrm{C}_{\mathrm{b}}$ 值与纤维素的 $\delta^{13} \mathrm{C}_{\mathrm{p}}$ 值相关很好, 将(1)式改写为

$$
\lambda \delta^{13} \mathrm{C}_{\mathrm{b}}=\delta^{3} \mathrm{C}_{\mathrm{a}}-4.4-22.6\left(P_{\mathrm{i}} / P_{\mathrm{a}}\right) \text {, }
$$

(2)式中 $\lambda$ 为 $\delta^{13} \mathrm{C}_{\mathrm{b}}$ 对 $\delta^{13} \mathrm{C}_{\mathrm{p}}$ 的系数. (2)式中 $\left(P_{\mathrm{i}} / P_{\mathrm{a}}\right)$ 项的系数为 22.6 , 远比 $\delta^{13} \mathrm{C}_{\mathrm{a}}$ 的系数 为大, 表明 $\delta^{13} \mathrm{C}_{\mathrm{b}}$ 的变化主要取决于 $\left(P_{\mathrm{i}} / P_{\mathrm{a}}\right)$ 比值的变化. $P_{\mathrm{i}}$ 和 $P_{\mathrm{a}}$ 间又有如下关系:

$$
P_{\mathrm{i}}=P_{\mathrm{a}}-A / g,
$$

(3)式中 $A$ 为植物对 $\mathrm{CO}_{2}$ 的吸收速率, $g$ 为叶片外部小孔的导通系数. 各种外部条件都可能 引起 $A, g$ 值的变化, 从而改变 $\delta^{13} \mathrm{C}_{\mathrm{b}}$ 值。 
鉴于晚冰期到冰后期气候曾有过多次冷暖波动这一事实,试对(2)、(3)式作一初步分析:

1. 冷期时, 气候恶劣, 植物生长季缩短, 光合作用强度减弱, 导致沼泽地上空大气中 $\mathrm{CO}_{2}$ 含 鼠升高 (这一点类似于冬季时森林上空大气 $\mathrm{CO}_{2}$ 含量的变化), 即 $P_{2}$ 值增高, $\left(P_{\mathrm{i}} / P_{\mathrm{a}}\right)$ 值 减小,使 $\delta^{13} \mathrm{C}_{\mathrm{b}}$ 值增大, 在 $\delta^{13} \mathrm{C}$ 曲线上表现为低的 $\delta^{13} \mathrm{C}$ 值.

2. 暖期时, 若尔盖高原夏季可能受到两种天气过程的影响一一西南季风和副热带高压的 识强. 但是这两种天气过程的加强是不完全同步的. 此时又可分两种情况: 第一种, 当西南 亟风占主导地位时, 气温和降水虽然增加, 但同时云量增多, 光照减弱, 导致 $g$ 值增大, 以接受 更多光源, 使纤维素细胞内部 $\mathrm{CO}_{2}$ 浓度升高, 即 $P_{\mathrm{i}}$ 值增大; 同时, 由于植物生长旺盛, 光合 作用强烈, 使沼泽地上空 $\mathrm{CO}_{2}$ 浓度降低, 即 $P_{2}$ 值减小, 结果 $P_{\mathrm{i}}$ 值增大而 $P_{3}$ 值减小, 导致 $\left(P_{\mathrm{i}} / P_{\mathrm{a}}\right)$ 比值增大, 从而 $\delta^{13} \mathrm{C}_{\mathrm{b}}$ 值减小, 在 $\delta^{13} \mathrm{C}$ 曲线上表现为高的 $\delta^{13} \mathrm{C}$ 值. 第二种情况, 当 㨽热带高压居主导地位时, 气温虽高但较干燥, 云量少, 辐射增强, 植物为减少蒸发, 会收缩或 关闭部分气孔, 使 $g$ 值减小, $P_{\mathrm{i}}$ 值随之降低. 因副高影响比季风小, 故 $\boldsymbol{P}_{\mathrm{i}}$ 值减小的幅度比 $P$. 小, 结果 $\delta^{13} \mathrm{C}_{\mathrm{b}}$ 值的减小幅度比第一种情况为小, 在 $\delta^{13} \mathrm{C}$ 曲线上则介于高低值之间的过

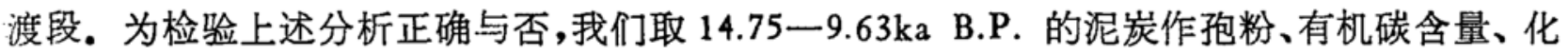
学元素及 $\mathrm{C} / \mathrm{N}$ 等多项分析,结果表明,各要素的变化对应关系都很好.

若尔盖高原泥炭有机碳 $\delta^{13} \mathrm{C}$ 曲线的变化显示, 本区自 $11.6 \mathrm{ka}$ B.P. 以来的气候经过几次 箱暂而剧烈的变化。

1. 有机碳 $\delta^{13} \mathrm{C}$ 曲线所示，若尔盖高原在全新世升温前的 $11.5-11.1 \mathrm{ka} \mathrm{B}$. P. 间出现了 知时间剧烈的降温事件，有机碳 $\delta^{13} \mathrm{C}$ 值下跌幅度达 $2.0 \%$ 。这是否相当于欧洲 $11.0-10.6 \mathrm{ka}$ 3.P. 间的晚仙女木 (Younger Dryas) 事件? 我们认为是可能的. 因为一是 ${ }^{14} \mathrm{C}$ 测年的精度 兒前还达不到要求, 二是本区位于中纬偏南的高海拔地区, 対气候变化较为敏感, 并受西南季 风影响, 与欧洲受北大西洋暖流影响不同, 因此冰后期以来出现的气候事件的时间不可能完全 一致. 䇥可桢先生在研究我国 5000 年以来的气候变化后得出结论,认为历史上寒冷期总是从 东亚向西波动传布到欧洲的以. 那么,5000 年前的气候波动是否也有类似现象? 不过,竺老是 以冬季温度作为标准, 而本文则从夏季温度着眼。

2. 依据有机碳 $\delta^{13} \mathrm{C}$ 曲线, 本区 12.0 - $3.5 \mathrm{ka}$ B. P. 间的气候曾出现过一系列的升温和降 温, 其中明显的升温期有 9.3-9.0,8.3,5.3ka B.P., 明显的降温期发生在 10.0-9.4, 8.8,6.1 和 $4.6 \mathrm{ka}$ B.P.

致谢 在有机碳 $\delta^{13} \mathrm{C}$ 的分析过程中得到刘禹、孙福庆和周杰同志多方面的指导, 在此一 并表示感谢。

\section{参考文献}

：1] 刘策谟、琳福庆、刘禹, 环境地球化学与健康, 第四集, 婴州科技出版社, 1991, 123-125.

[2] 镍石、陈文正, 䤀问位索地质学概论,地质出版社, 1983,54-58.

[3] 刘荣谟、刘禹、周卫健等, 黄土 - 第四纪地质 - 全球变化,第一第, 科学出版社, 1990,7-11.

14] Feancey, R. J., Fraguhar, G. D., Nature, 1982,297(5861): 28-31.

[5] 䇥可桢文集,科学出版社, $1979,494-497$. 